\title{
VENOUS INSUFFICIENCY AND THROMBOEMBOLIC DISEASE IN BARIATRIC SURGERY PATIENTS
}

\author{
Bonno van BELLEN'1 Ivan de Barros GODOY ${ }^{1}$, Andrea Almeida REIS ${ }^{1}$ and \\ Pedro BERTEVELLO2
}

\begin{abstract}
Context - Morbid obesity is associated with various co-morbidities, including chronic venous insufficiency. Bariatric surgery is the only effective treatment for morbid obesity, but with potential risks and possible complications, including venous thromboembolism. Objective - To determine the prevalence of clinical and ultrasonographic signs of chronic venous insufficiency in morbid obese patients in preparation for bariatric surgery and the incidence of post-operative venous thromboembolic disease. Methods - Patients on work-up for bariatric surgery of Centro Terapêutico Especializado em Fígado (CETEFI) and Pro-Gastro surgical teams of the Hospital Beneficência Portuguesa de São Paulo were included. The analysed data were pre-operative findings for venous insufficiency (CEAP - clinical, etiological, anatomical, physiopathologic - classification and venous ultrassonographic findings), type of surgery (open or laparoscopic), abdominal circumference, body mass index (BMI) and post-operative ultrassonography search for venous insufficiency and deep venous thrombosis. Results - Between March 2007 and December 2009, 95 patients candidates for bariatric surgery had clinical and duplex scan evaluation of the lower limbs venous system. Of the 95 patients, 53 were submitted to the surgical procedure. There was a predominance of women (77.9\%), the average age was 38.5 years, average preoperative weight $124.6 \mathrm{~kg}$ and average BMI of $45.5 \mathrm{~kg} / \mathrm{m}^{2}$. Regarding obesity, $16.8 \%$ were obese, and $83.1 \%$ were morbidly obese. In relation to the venous findings, $86.3 \%$ of the patients did fit CEAP classification less than 3 and $13.7 \%$ greater than or equal to 3 . Among the post-operative complications, there were four cases of wound infection. Three patients developed post-operative distal venous thrombosis (7.5\%), but no one had clinically manifested pulmonary embolism. Conclusion - No relation between BMI, CEAP classification and venous ultrassonographic findings were found. Although prophylaxis was used in all patients, the incidence of post-operative distal venous thrombosis was considerably high.
\end{abstract}

HEADINGS - Venous insufficiency. Venous thromboembolism. Bariatric surgery. Morbid obesity.

\section{INTRODUCTION}

The 1991 Conference for the Development of Consensus of the National Institute of Health of the United States, decided that bariatric surgery is an option for weight loss in patients with body mass index higher than $40 \mathrm{Kg} / \mathrm{m}^{2}$ or higher than $35 \mathrm{Kg} / \mathrm{m}^{2}$ with additional weight-related morbidity and in which there was no success in weight loss programs ${ }^{(1)}$.

Obesity is linked to hypertension, diabetes, degenerative joint diseases, gastro-esophageal reflux, sleep apnea syndrome, venous insufficiency, hypoventilation syndrome, hernias of the abdominal wall and cerebral pseudotumor ${ }^{(1)}$. Chronic venous insufficiency can manifest itself by edema of the legs, varicose veins, venous ulcers and ochre dermatitis, refractory to treatment $t^{(6)}$. Weight loss provided by restriction/ mal-absorption surgery may result in improvement of these comorbidities ${ }^{(7)}$.

Patients who are candidates for bariatric surgery are at high-risk mainly because of the associated co-morbidities and the procedure can result in various types of complications ${ }^{(1)}$.

In conventional surgery (open gastroplasty), the most common complications are deep venous thrombosis, pulmonary embolism, pulmonary atelectasis, technical problems of anastomosis, hernias and wound infection ${ }^{(1)}$. For laparoscopic surgery, the most frequent complications are primarily those related to peritoneal distention, such as metabolic acidosis, cardiac arrhythmias, deep venous thrombosis and pulmonary embolism $^{(1)}$.

The incidence of venous thrombosis of the lower limbs after bariatric surgery is considered to be low even in laparoscopic approach although in this type of procedure, increased venous stasis is an important component ${ }^{(4,9)}$. Increased intra-abdominal pressure causes decrease in venous flow in the legs, increasing venous stasis.

This study aims to evaluate the importance of

Serviço de Cirurgia Vascular Integrada of the Hospital da Beneficencia Portuguesa, São Paulo; ${ }^{2}$ Progastro, Hospital da Beneficência Portuguesa, São Paulo, Brasil. Corresponcence: Bonno van Bellen. Rua Maestro Cardim 925 - 01323-001, São Paulo, SP, Brasil. E-mail bellen@apm.org.br 
venous stasis in morbid obese patients, and its relations to the degree of obesity and check its correlation with postoperative thromboembolic events and with other risk factors such as age, sex, body mass index, abdominal circumference.

\section{METHODS}

This is a prospective, observational, epidemiological, longitudinal study, for the determination of the prevalence of clinical and ultrasonographic signs of chronic venous insufficiency in morbid obese patients and its correlation with the incidence of postoperative deep vein thrombosis and pulmonary embolism.

The study was approved by the Committee for Medical Ethics of the Beneficencia Portuguesa Hospital of São Paulo.

The patients selected for this study were on work-up for bariatric surgery by two different services: Centro Terapêutico Especializado em Fígado (CETEFI) and Pro-Gastro during the period from March 2007 to December 2009. All agreed to participate, having signed the informed consent.

The assessment of the lower limb venous system was done pre-operatively by eco color Doppler and again between 25 and 35 days after surgery. This evaluation was performed by the same operator and with the same instrument.

The standardization of prophylaxis for deep vein thrombosis consisted of $40 \mathrm{mg}$ subcutaneous enoxaparin every 12 hours during the whole postoperative in-hospital period, associated with elastic stockings and early deambulation ${ }^{(3,5)}$.

The events of primary interest were the clinical findings, CEAP (clinical, etiological, anatomical, physiopathologic) classification for chronic venous disease ${ }^{(2)}$ and ultrassonographic findings, by which post-operative possible clinical improvement of chronic venous insufficiency up to 35 days after surgery could be assessed, as could the presence of deep venous thrombosis. The occurrence of pulmonary embolism was evaluated only on the basis of clinical symptoms. We considered secondary interest events: the type of surgery (open or laparoscopic), the abdominal circumference, body mass index.

The data were evaluated to determine independent factors related to the development of venous stasis.

For statistical analysis the Fischer's test was used, the Chi-square for independent equality of two ratios and the Mann-Whitney test. For complementation of quantitative descriptive analysis, the technique of confidence interval for the mean was used. The considered significance level was $0.05(5 \%)$ and confidence intervals constructed with $95 \%$ statistical confidence.

The CEAP classification for venous insufficiency according to the consensus established in 1994 at the American Venous Forum and revised in 2004 ${ }^{(2)}$, was used only for the clinical classification $(\mathrm{C})$ :

$\mathrm{C}_{0}-$ no visible nor palpable signs of venous disease;

$\mathrm{C}_{1}$ - presence of reticular veins or teleangectasis;

$\mathrm{C}_{2}$ - presence of varicose veins;

$\mathrm{C}_{3}$ - presence of edema;

$\mathrm{C}_{4}$ - presence of skin changes such as hyperpigmentation, eczema or dermatoesclerosis;
$\mathrm{C}_{5}$ - presence of healed venous ulcer;

$\mathrm{C}_{6}$ - presence of active venous ulcer.

Patients were considered in two groups: CEAP classification less than $\mathrm{C}_{3}$ and equal or higher than $\mathrm{C}_{3}$.

Regarding obesity, patients were divided into groups according to the body mass index:

- Severe obese (with index between 30 and 40);

- Morbidly obese (index equal to or greater than 40)(1).

Regarding the echo color Doppler findings, patients were grouped as normal or abnormal. The result was defined as abnormal when there was significant reflux in the internal saphenous veins, perforating veins and deep veins and, if there were signs of previous deep venous thrombosis.

About the abdominal circumference, the grouping of patients was set when greater than or lesser than $100 \mathrm{~cm}$.

\section{RESULTS}

Ninety-five patients were included in this study, of which 53 were effectively operated. The others gave up the procedure or were excluded on the basis of some clinical contra-indication for surgery.

Among the patients, 74 were female $(77.9 \%)$, the median age was 38.5 years, the average preoperative weight $124.6 \mathrm{~kg}$ and the average BMI was $\left.45.5 \mathrm{~kg} / \mathrm{m}^{2}\right)($ Table 1$)$.

In relation to clinical classification of obesity, $16.8 \%$ (16 patients) were severely obese and $83.2 \%$ (79 patients) were morbidly obese (Table 1).

TABLE 1. Demographic data of the patients

\begin{tabular}{lcc}
\hline & N & $\%$ \\
\hline Total of patients & 95 & \\
Number of operated patients & 53 & \\
Females & 74 & 77.9 \\
Males & 21 & 22.1 \\
Average age in years & 38.5 & \\
Average weight in kg & 124.6 & \\
Average BMI in kg/m ${ }^{2}$ & 45.5 & \\
Severely obese & 16 & 16.8 \\
Morbid obese patients & 79 & 83.2 \\
CEAP 0 & 12 & 12.6 \\
CEAP 1 & 41 & 43.2 \\
CEAP 2 & 29 & 30.5 \\
CEAP <3 & 82 & 86.3 \\
CEAP 3 & 8 & 8.4 \\
CEAP 4 & 3 & 3.2 \\
CEAP 5 & 1 & 1.1 \\
CEAP 6 & 1 & 1.1 \\
CEAP $\geq 3$ & 13 & 13.8 \\
Normal ultrasound & 69 & 72.6 \\
Abnormal ultrasound & 17 & 17.9 \\
Ultrasound with no consistent results & 9 & 9.5 \\
\hline
\end{tabular}

BMI = body mass index 
As regarding to venous insufficiency, $12(12.6 \%)$ patients had a CEAP classification of zero, $41(43.2 \%)$ had CEAP equal to $1,29(30.5 \%)$ CEAP equal to $2,8(8.4 \%)$ CEAP equal $3,3(3.2 \%)$ CEAP equal to $4,1(1.1 \%)$ CEAP equal to 5 and $1(1.1 \%)$ CEAP equal to 6 . Considering the CEAP grouping, $82(86.3 \%)$ patients were classified below 3 and 13 $(13.7 \%)$ patients were equal or above 3 (Table 1 ).

With regard to the ultrasound examination, $69(72.6 \%)$ patients had a normal exam, $17(17.9 \%)$ had an abnormal examination, and $9(9.5 \%)$ were not examined for various reasons. Among the ultrasound examinations that showed abnormalities, 14 patients had valve insufficiency of the greater saphenous vein and the remaining had varicosities or insufficient perfurators. In no case there were signs of previous venous thrombosis. (Table 1)

Among the 53 patients operated, the average length of stay was 4.75 days. Conventional open surgery was performed in 39 patients $(73.6 \%)$ and in the remaining $14(26.4 \%)$ laparoscopic surgery was performed.

Regarding the surgical complications, there were four cases of wound infection, accounting for $7.5 \%$ of the operated cases. There were three $(5.7 \%)$ cases of postoperative venous thrombosis detected by ultrasound. In all cases thrombosis occurred distally to the popliteal vein. No patient presented clinical signs of pulmonary embolism.

\section{Association between BMI and CEAP}

Among the 16 obese patients, $14(87 \%)$ had venous disease classified as CEAP below 3 and the other $2(12.5 \%)$, CEAP equal or above 3 .

Of the 79 patients with morbid obesity, $68(86.1 \%)$ had venous disease classified as CEAP below 3 and $11(13.9 \%)$ had CEAP classification equal or above 3 .

There was no statistical difference between the two groups $(P=1.000)($ Table 2$)$.

TABLE 2. Association between obesity expressed in body mass index (BMI) and CEAP classification of venous insufficiency

\begin{tabular}{lllllllr}
\hline & \multicolumn{9}{c}{ BMI } \\
\cline { 2 - 7 } CEAP & \multicolumn{2}{c}{ Obese } & \multicolumn{2}{c}{ Morbid obese } & \multicolumn{2}{c}{ Total } \\
& $\mathrm{N}$ & $\%$ & $\mathrm{~N}$ & $\%$ & $\mathrm{~N}$ & $\%$ \\
\hline$<3$ & 14 & 83.5 & 68 & 86.1 & 82 & 86.3 \\
$\geq 3$ & 2 & 12.5 & 11 & 13.9 & 13 & 13.7 \\
Total & 16 & 16.8 & 79 & 83.2 & 95 & 100 \\
\hline$P<0.001$ & \multicolumn{10}{c}{} & & & & &
\end{tabular}

\section{Association between $\mathrm{BMI}$ and ultrasound}

Of the 15 obese patients in who venous ultrasonography was done, $4(26.7 \%)$ had an abnormal examination and 11 $(73.3 \%)$ had a normal scan.

Among the 70 morbidly obese patients in which the exam was done, $12(17.1 \%)$ had an abnormal examination and 58 $(82.9 \%)$ had a normal scan.

There was no statistically significant difference between these findings $(P=0.467)$ (Table 3$)$.

\section{Association between CEAP and abdominal circumference}

The average abdominal circumference of the 82 patients with CEAP below 3 was $129.32 \mathrm{~cm}$ whereas in the 13 patients with CEAP equal or above 3 the circumference was $140.23 \mathrm{~cm}$. This difference was statistically significant $(P=0.028)$.

\section{Association between abdominal circumference and ultrasonographic findings}

Normal ultrasound results occurred in patients with $131.5 \mathrm{~cm}$ average abdominal circumference whereas abnormal results occured in patients with an average of 131.0 $\mathrm{cm}$ abdominal circumference. These results are statistically $\operatorname{similar}(P=0.392)$.

\section{Association between BMI and deep venous thrombosis}

The three cases of deep vein thrombosis occurred in morbidly obese patients. Although there have been no case among the obese, there was no statistical significance $(P=1.00)$. Similarly, there was no significance regarding the occurrence of thrombosis in relation to the abdominal circumference.

\section{Association between type of surgery and deep venous thrombosis}

The three cases of deep venous thrombosis occurred in patients submitted to open surgery. Although there were no cases among the patients who had laparoscopic surgery, there was no statistical difference between the occurrence of this complication.

\section{DISCUSSION}

Among the co-morbidities of morbid obesity is chronic venous insufficiency, which in turn is a risk factor for deep vein thrombosis, notably when the patient undergoes surgery. One of the factors that favors venous stasis in the obese is probably high intra-abdominal pressure due to the obesity itself. This high abdominal pressure results in increased pressure upon the inferior vena cava, iliac and femoral veins, which in turn diminishes venous flow and therefore result in venous valve insufficiency, leading to chronic venous stasis causing swelling, dermatitis, eczema, and finally venous ulcer. The occurrence of chronic venous insufficiency syndrome was observed in $3.6 \%$ of 1976 patients reported by Sugerman $\mathrm{HJ}^{(8)}$ and occurred in individuals with a BMI of $61 \pm 12 \mathrm{~kg} / \mathrm{m}^{2}$ or weight of $179 \pm 39 \mathrm{~kg}$, therefore within the group of mor-

TABLE 3. Association between CEAP classification and ultrasonographic findings

\begin{tabular}{lcccccc}
\hline \multirow{2}{*}{ US } & \multicolumn{2}{c}{ Obese } & \multicolumn{2}{c}{ Morbid obese } & \multicolumn{2}{c}{ Total } \\
& $\mathbf{N}$ & $\%$ & $\mathbf{N}$ & $\%$ & $\mathbf{N}$ & $\%$ \\
\hline Normal & 11 & 73.3 & 58 & 82.9 & 69 & 72.6 \\
Abnormal & 4 & 26.7 & 12 & 17.1 & 16 & 16.8 \\
Total & 15 & 15.7 & 80 & 84.2 & 95 & 100 \\
\hline
\end{tabular}

$P=0.467$ 
bidly obese. In the population here presented, comparing the CEAP classification among the two groups of obesity (obese vs morbid obese) no correlation was observed between the degree of obesity and the clinical classification of venous disease. Also there was no statistically significant difference between the degree of obesity and the changes observed in the ultrasonographic examination. It can be assumed that the older the patient, the greater should be the impact of obesity upon the venous stasis. Although it is not possible to compare from the statistical point of view, the group analysed by Sugerman had an average age of $44+/-10$ years, while the average age of our group was 38.5 years.

On the other hand, analyzing the relationship between abdominal circumference and venous disease, we observed statistically significant difference regarding the CEAP, i.e. patients classified as CEAP lower than 3 , had an average abdominal circumference of $129.32+/-3.09$, statistically different from $140,23+/-11.52$ for those who had a CEAP classification of $\geq 3$. However, no correlation could be observed between abdominal circumference and the ultrassonographic examination.

The ultrasound examination performed 25 to 35 days after surgery, did not show any modification regarding the pre-operative findings. Sugerman showed improvement in venous stasis in his patients followed for 5 years after bariatric intervention ${ }^{(3)}$. Surely these data cannot be compared with those of our patients since our follow up was too short.

Regarding thromboembolic disease, bariatric surgery is considered as being of moderate risk, and pharmacological prophylaxis is recommended ${ }^{(11)}$. Despite the fact that this recommendation is not new, some authors do not see the need for prophylaxis considering the low incidence of thromboembolic disease found in their operated populations. Westling ${ }^{(10)}$ found distal vein thrombosis in only two patients of the 116 operated, without prophylaxis. In 1978 , Printen asserted that he did not recommend prophylaxis, because the risks would be greater than the benefits. He based his affirmation on a retrospective study of 564 patients undergoing bariatric surgery without prophylaxis. There were four deadly pulmonary embolisms and three others without complications.

On the other hand, Stern, in 2005, in a systematic review found that the relative risk for pulmonary embolism of patients undergoing bariatric surgery is 2.21 , being females below 40 years of age at higher risk.

If there is no consensus among surgeons about the need to perform prophylaxis, there is neither consensus regarding the dosage to be used. Schelten compared two groups of patients: $30 \mathrm{mg}$ enoxaparin twice a day in 92 patients and $40 \mathrm{mg}$ enoxaparin twice a day in 380 patients. Patients had also intermittent pneumatic compression or used elastic stockings. In the first group, with the lower dose, five cases of venous thrombosis were detected (5.4\%). In the other group, with higher dose, there were two cases of venous thrombosis, corresponding to $0.6 \%$. This difference was statistically significant. There was one case in each group with bleeding complications.

Hamad analysed 668 patients in a retrospective study of five different centers in which $40 \mathrm{mg}$ of enoxaparin was used for 10 days postoperatively. There were six $(0.9 \%)$ cases of pulmonary embolism and one $(0.1 \%)$ case of deep venous thrombosis. In six $(0.9 \%)$ patients occurred bleeding complications.

A survey carried out by Wu in 2000 among the members of the American Society of Bariatric Surgery, shows that $86 \%$ of surgeons feel that patients submitted to bariatric surgery, are at risk of developing thromboembolic disease. They reported an incidence of venous thrombosis of $2.63 \%$ and $0.95 \%$ of pulmonary embolism. The most important is that $95 \%$ of the surgeons claimed they use prophylaxis: $50 \%$ with mini-dosis heparin, $33 \%$ by intermittent compression by, $13 \%$ by low molecular weight heparin and $4 \%$ by other methods.

Thus, it seems that most surgeons use prophylactic protection for their patients. As regarding the dose, it usually is higher than used in conventional prophylaxis: 60 to $80 \mathrm{mg}$ of enoxaparin per day.

In the group under study, prophylaxis was done with $80 \mathrm{mg}$ enoxaparin per day, as well as additional measures have been used, such as elastic stockings and early ambulation.

Even so, a high index of venous thrombosis occurred $(5.7 \%)$ as compared to the literature. It should be noted that the $5.4 \%$ occurrence reported by Schelten happened in patients in whom prophylaxis was done with $60 \mathrm{mg}$ enoxaparin per day, while in those in which the incidence was $0.6 \%$ the used dose was $80 \mathrm{mg}$ enoxaparin.

It is possible that this difference is due to the fact that the ultrassonographic examination was done between 25 and 35 days after surgery. The before mentioned data were obtained in still hospitalized patients. In these circumstances venous thrombosis may not be detectable since early thrombus has an acoustic interface very similar to the normal blood.

\section{CONCLUSION}

Obesity is linked to numerous co-morbidities and bariatric surgery is a viable option for treatment. The surgical procedure has a risk for thromboembolic events due to changes of venous flow.

Our study suggests that prophylaxis with use of elastic stockings, early post-operative ambulation and administration of $40 \mathrm{mg}$ enoxaparin every 12 hours during hospitalization, goes along with a considerable high incidence of venous thrombosis although pulmonary embolism was not detected. 
van Bellen B, Godoy IB, Reis AA, Bertevello P. Insuficiência venosa e doença tromboembólica em pacientes submetidos a cirurgia bariátrica. Arq Gastroenterol. 2013,50(3):191-5.

RESUMO - Contexto - A obesidade mórbida está associada a várias comorbidades, dentre elas a estase venosa crônica. A cirurgia bariátrica é a única modalidade efetiva de tratamento, porém com riscos e possibilidade de complicações, inclusive o tromboembolismo venoso. Objetivos - Determinar a prevalência de sinais clínicos e ultrassonográficos de insuficiência venosa crônica no paciente obeso mórbido candidato a cirurgia bariátrica e a incidência de trombose venosa profunda. Métodos - Foram selecionados para este estudo os pacientes candidatos a cirurgia bariátrica das equipes Centro Terapêutico Especializado em Fígado (CETEFI) e Pró-Gastro do Hospital Real e Benemérita Sociedade Portuguesa de Beneficência de São Paulo no período de março de 2007 a dezembro de 2009. Os dados analisados foram os achados clínicos (classificação CEAP - clínica, etiologia, anatomia e patofisiologia - classificação da estase venosa crônica) e sinais ultrassonográficos, o tipo de cirurgia (aberta ou laparoscópica), a circunferência abdominal, o índice de massa corpórea (IMC), o tempo de internação hospitalar e presença de comorbidades. A avaliação foi realizada para encontrar fatores independentes relacionados com a estase venosa. Resultados - Entre março de 2007 e dezembro de 2009 , 95 pacientes candidatos a cirurgia bariátrica foram avaliados clinicamente e por ultrassonografia duplex scan de sistema venoso de membros inferiores. Dos 95 pacientes, 53 acabaram sendo submetidos à cirurgia. Houve predominância de mulheres $(77,9 \%)$, a idade média foi de 38,5 anos, a média de peso pré-operatório $124,6 \mathrm{~kg}$ e IMC médio de 45,5 kg/m². Quanto à obesidade, 16,8\% eram obesos graves, 78,9\% obesos mórbidos e 4,2\% mega-obesos. Em relação à avaliação venosa clínica, $86,3 \%$ dos pacientes se enquadravam na classificação CEAP menor que 3 e 13,7\% maior ou igual a 3 . Dentre as complicações pós-operatórias, houveram quatro casos de infecção de ferida. Não houve nenhum caso de trombose venosa e embolia pulmonar no pós-operatório. Conclusão - Não foi encontrada correlação entre IMC, classificação CEAP e achados ultrassonográficos. Apesar de ter sido feita profilaxia para trombose venosa distal pós-operatória em todos os pacientes, a incidência foi consideravelmente elevada.

DESCRITORES - Insuficiência venosa. Tromboembolia venosa. Cirurgia bariátrica. Obesidade mórbida.

\section{REFERENCES}

1. Buchwald H; Consensus Conference Panel. Consensus conference statement bariatric surgery for morbid obesity: health implications for patients, health professionals, and third-party payers. Surg Obes Relar Dis. 2005;1:371-81.

2. Eklöf B, Rutherford RB, Bergan JJ, Carpentier PH, Gloviczki P, Kistner RL, Meissner MH, Moneta GL, Myers K, Padberg FT, Perrin M, Ruckley CV, Smith PC, Wakefield TW; American Venous Forum International Ad Hoc Committee for Revision of the CEAP Classification. Revision of the CEAP classification for chronic venous disorders: consensus statement. J Vasc Surg. 2004;40;1248-52.

3. Hamad GG, Choban PS. Enoxaparin for thromboprophylaxis in morbidly obese patients undergoing bariatric surgery: findings of the prophylaxis against VTE outcomes in bariatric surgery patients receiving enoxaparin (PROBE) study. Obes Surg. 2005;15:1368-74.

4. Kearon C, Akl EA, Comerota AJ, Prandoni P, Bounameaux H, Goldhaber SZ, Nelson ME, Wells PS, Gould MK, Dentali F, Crowther M, Kahn SR; American College of Chest Physicians. Antithrombotic therapy for VTE disease : antithrombotic therapy and prevention of thrombosis, 9th ed: American College of Chest Physicians Evidence-Based Clinical Practice Guidelines. Chest. 2012;141:e419S-94S.
5. Printen KJ, Miller EV, Mason EE, Barnes RW. Venous thromboembolism in the morbidly obese. Surg Gynecol Obstet. 1978;147:63-4.

6. Scholten DJ, Hoedema RM, Scholten SE. A comparison of two different prophylactic dose regimens of low molecular weight heparin in bariatric surgery. Obes Surg. 2002;12:19-24.

7. Stein PD, Beemath A, Olson RE. Obesity as a risk factor in venous thromboembolism. Am J Med. 2005;118:978-80.

8. Sugerman HJ. Effects of increased intra-abdominal pressure in severe obesity. Surg Clin North Am. 2001;81:1063-75.

9. Sugerman HJ, Sugerman EL, Wolfe L, Kellum JM Jr, Schweitzer MA, DeMaria EJ. Risks and benefits of gastric bypass in morbidly obese patients with severe venous stasis disease. Ann Surg. 2001;234:41-6.

10. Westling A, Bergqvist D, Boström A, Karacagil S, Gustavsson S. Incidence of deep venous thrombosis Incidence in patients undergoing obesity surgery. World J Surg. 2002;26:470-3.

11. Wu EC, Barba CA. Current practices in the prophylaxis of venous thromboembolism in bariatric surgery. Obes Surg. 2000;10:7-14

Received 18/12/2012 Accepted 8/5/2013. 